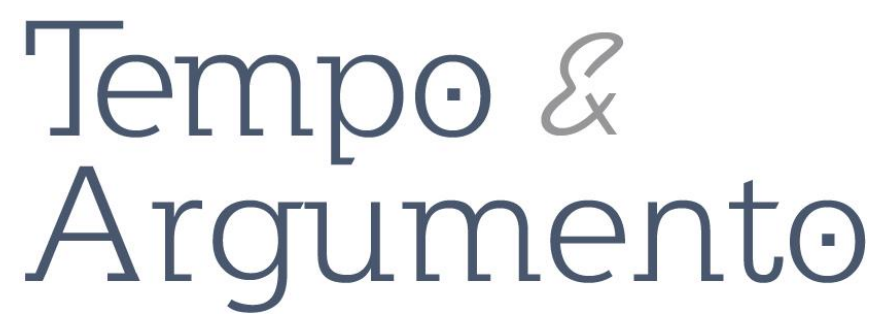

\title{
Os Direitos Humanos e a História ${ }^{1}$
}

\author{
Autor da Obra

\section{Stefan-Ludwig Hoffmann} \\ Professor do Departamento de História da \\ Universidade da Califórnia, Berkeley. \\ slhoffmann@berkeley.edu
}

\section{DOI: $10.5965 / 2175180311272019525$}

http://dx.doi.org/10.5965/2175180311272019525

Os historiadores são os embalsamadores das nossas convicções políticas e morais. Assim que a historiografia começa a se interessar por uma questão, podemos ter certeza de que ela já não possui uma relevância autoevidente em nossa sociedade. Alguns problemas e questões só se tornam objetos da história depois de a sociedade se tornar historicamente consciente deles. A história dos trabalhadores desabrochou nos anos 1970, por exemplo, quando o trabalho industrial estava em processo de desaparecimento, assim como a memória e seus locais se tornaram um modo de pesquisa para os historiadores nos anos 1980, precisamente quando a memória vivida da "era dos extremos" (Eric Hobsbawm) desaparecia juntamente com sua última geração.

\footnotetext{
* Tradução do texto "Human Rights and History", de Stefan-Ludwig Hoffmann, publicado na revista Past \& Present, Volume 232, Issue 1, August 2016, Pages 237-278, https://doi.org/10.1093/pasti/gtw011.

** Tradução: Filipe dos Santos Avila e Meggie Rosar Fornazari.

*** Revisão: Fernando Coelho e Silvia Maria Fávero Arend

1 Pelos comentários e sugestões, sou grato às plateias do Humans Rights Seminar, University of California, Berkeley; Davis Center Seminar, Princeton University; Rethinking Modern Europe Seminar, Institute for Historical Research, University of London; European Crises from Weimar until Today: History-Economy-Politics-Law, Copenhagen Business School, 2014; The Good Years! Historical Trajectories, 1980-2010, ETH Zurich, Monte Verità, 2015; e, finalmente, do Seventh Gerald Stourzh Lecture on the History of Human Rights and Democracy, University of Vienna, 2015.
} 
A questão dos direitos humanos não chegou, de modo nenhum, tão longe, embora certa sobriedade historicizadora se tenha firmado agora entre os ativistas. ${ }^{2}$ Pelo contrário, como argumentei em outro lugar, os direitos humanos ainda são algo como a doxa da nossa época: aquelas ideias e sentimentos que se pressupõe tacitamente que sejam verdades autoevidentes e sem necessidade de qualquer justificativa. ${ }^{3}$ Quem se opõe aos direitos humanos atualmente? E quem entre os nascidos antes do final do século XX gostaria de ser lembrado de que, antes, teria usado muito pouco o conceito de direitos humanos? Pelo menos no mundo euro-atlântico atual a ressonância dos direitos humanos é tão universal e inatacável que, em princípio, a única coisa que ainda se debate é como eles podem ser melhor efetivados em escala global. Sentimo-nos angustiados e melancólicos com a contínua violação dos direitos humanos no nosso tempo, mas não desejamos abandonar completamente o conceito.

Ainda assim, chama a atenção que historiadores começaram a se preocupar com os direitos humanos apenas recentemente - essencialmente no final dos anos 1990. Contudo, as maiores sínteses históricas das últimas duas décadas, por exemplo nas intepretações de Eric Hobsbawm e Tony Judt do século XX, ou do século XIX por Jürgen Osterhammel e Chris Bayly, ou da ascensão e queda de impérios por Jane Burbank e Fred Cooper, os direitos humanos aparecem apenas nas margens, isso quando mencionados. A maioria dos historiadores de genocídio, refugiados, nacionalismo, escravidão ou humanitarianismo (incluindo-se Pamela Ballinger, desde 2011 a primeira professora de história dos direitos humanos nos Estados Unidos) ${ }^{4}$ não se consideram parte do novo campo da história dos direitos humanos. Isso está prestes a mudar, e muito já pode ser dito a respeito. Recentemente nós aparentemente chegamos a um novo presente, uma era de "governança global",

\footnotetext{
2 Stephen Hopgood, The Endtimes of Human Rights (Ithaca, 2013).

3 Stefan-Ludwig Hoffmann, 'Introduction: Genealogies of Human Rights', in Stefan-Ludwig Hoffmann (ed.), Human Rights in the Twentieth Century (New York, 2010), 2.

${ }^{4}$ Pamela Ballinger, 'The History of Human Rights: The Big Bang of an Emerging Field or Flash in the Pan?', New Global Studies, vi (2012), 3.
} 
A nova historiografia dos direitos humanos pode ser dividida em duas tendências: uma que busca pontos de estabilidade para o presente e os encontra na evolução de longa duração dos direitos humanos (a história profunda), e outra que busca demonstrar, de forma revisionista, a instabilidade de tais narrativas universalistas e, portanto, a historicidade, ou seja, a transitoriedade das nossas convicções políticas e morais (a história recente). Convenientemente, essas duas tendências se agrupam em torno de duas obras pioneiras: Inventing Human Rights de Lynn Hunt e, como contraposição, Last Utopia de Samuel Moyn. ${ }^{5}$

De forma resumida, Lynn Hunt argumenta que, no século XVIII, os direitos humanos se tornaram mais corriqueiros porque eram baseados em novas experiências e práticas culturais: um novo regime emocional, cujo centro era a "empatia imaginada". Desse novo regime emocional, que é evidente, por exemplo, tanto em romances epistolares e sentimentais quanto em campanhas morais pela abolição da tortura no começo da década de 1760, surgiu um novo regime legal durante a Revolução Francesa, que, por sua vez, seguiu a sua própria lógica em cascata: uma vez que os direitos humanos adquiriram sua autoevidência, eles já não podiam ser removidos do mundo, e se desdobraram em potencial revolucionário durante os séculos XIX e XX. A leitura de romances epistolares ou relatos de tortura tinha efeitos físicos, que se traduziam em "mudanças no cérebro" e "voltavam à tona" como novos conceitos de direitos humanos individuais. Hunt reconhece os paradoxos de direitos humanos como a política, que as reivindicações de direitos surgiam de pari passu com a violência revolucionária, mas insiste que sua autoevidência

\footnotetext{
${ }^{5}$ Lynn Hunt, Inventing Human Rights: A History (New York, 2007); Samuel Moyn, Last Utopia: Human Rights in History (Cambridge, Mass., 2010).
} 
falar de direitos humanos na forma atual, já que os direitos individuais só foram garantidos para todas as pessoas, mesmo além do Estado-nação, somente após os anos 70 - a partir de Jimmy Carter e a era disco, como resumido por um infeliz analista.7 Antes disso, os direitos humanos eram amarrados ao Estado-nação e eram portanto, essencialmente, direitos de cidadania. Como o título sugere, os direitos humanos, segundo Moyn, se tornaram a última utopia, principalmente para os ativistas das organizações não governamentais de direitos humanos recentemente criadas, como a Anistia Internacional, na sequência do fracasso de outras ideologias globais de emancipação como o socialismo e o anticolonialismo. Com essa brilhante polêmica, Moyn fornece um modelo interpretativo para uma série de estudos mais recentes e projetos de pesquisa em andamento de uma nova geração de historiadores que pesquisam o "avanço" dos direitos humanos rumo a uma moralidade global nos anos $70 .^{8}$

Este ensaio pretende ser uma intervenção historiográfica neste debate e desenvolve três argumentos interconectados, os quais buscam determinar o local

\footnotetext{
${ }^{6}$ Hunt, Inventing Human Rights, 33, 214. Ver também Lynn Hunt, 'The Paradoxical Origins of Human Rights', in Jeffrey N. Wasserstrom et al. (eds.), Human Rights and Revolutions, 2nd edn (Lanham, 2007). Mais explícito é Dan Edelstein, The Terror of Natural Right: Republicanism, the Cult of Nature, and the French Revolution (Chicago, 2009); Dan Edelstein, 'Enlightenment Rights Talk', Journal of Modern History, Ixxxvi (2014), 562: "Já que os direitos naturais são a prorrogativa de uma pessoa senciente, aqueles que, nas palavras de Rousseau, são 'surdos à gentil voz da natureza', poderiam nunca conhecer qualquer 'verdadeiro sentimento de justiça e humanidade.' Já que esses monstros não podiam ser melhorados, eles deviam ser destruídos (étouffés). Os revolucionários de 1793 não abandonaram o espírito universalizante da declaração de 1789: este espírito nunca esteve lá. Assim como ninguém simpatizava com os vilões, geralmente aristocráticos, dos romances sentimentais, os revolucionários franceses não demonstrariam muita contenção aos opositores, geralmente aristocráticos, do novo regime."

7 Gary J. Bass, 'The Old New Thing', New Republic, 20 Oct. 2010.

${ }^{8}$ Ver, por exemplo, Jan Eckel e Samuel Moyn (eds.), The Breakthrough: Human Rights in the 1970 s (Philadelphia, 2014); Jan Eckel, Die Ambivalenz des Guten: Menschenrechte in der internationalen Politik seit den 1940ern (Göttingen, 2014). Este argumento apareceu pela primeira vez em Kenneth Cmiel, 'The Emergence of Human Rights Politics in the United States', Journal of American History, Ixxxvi (1999), 1233; Kenneth Cmiel, 'The Recent History of Human Rights', American Historical Review, civ (2004). Para uma crítica útil, ver Robert Brier, 'Beyond the Quest for a "Breakthrough": Reflections on the Recent Historiography of Human Rights', European History Yearbook, xvi (2015).
} 
dos direitos humanos nas crises e conflitos do passado recente. Primeiramente, eu gostaria de levar o revisionismo histórico de Moyn e outros ainda mais adiante e argumentar que nós podemos falar primeiro de direitos humanos individuais como um conceito básico (Grundbegriff), ou seja, como um conceito contestado, insubstituível e consequencial da política global, somente nos anos 1990, após o fim da Guerra Fria. Nos anos 1970 e 1980, os "direitos humanos" coexistiam e se sobrepunham a outras expressões morais e políticas como "solidariedade" e incluíam noções concorrentes de direitos, que ainda eram tributárias, de diversas formas, aos legados do socialismo e do anticolonialismo, como, por exemplo, o movimento transnacional contra o apartheid. Foi apenas após o fim da Guerra Fria que os "direitos humanos" surgiram como um modelo explicativo para entender o que acabara de acontecer. Eu argumentarei que o idealismo dos direitos humanos não é a causa, mas a consequência das rupturas de época do final do século XX.

Entretanto, isso não quer dizer que, em segundo lugar, os "direitos humanos" não possuam uma história mais profunda: aqui eu concordo com Hunt e outros. Pelo contrário, em muitos sentidos o idealismo dos direitos humanos dos anos 1990 aparece como um estranho retorno ao liberalismo iluminista do final do século XVIII e século XIX e seus críticos (Immanuel Kant e Carl Schmitt, as duas fontes de inspiração e antípodas do discurso político e moral dos anos 1990), assim como o entusiasmo pelo cosmopolitismo, pela sociedade civil, pelo livre comércio, pelas intervenções humanitárias e pelas justificações morais da guerra na nova (des)ordem mundial. Eu sugiro, portanto, que nós deveríamos trazer o longo século XIX de volta à história dos direitos humanos, particularmente as histórias dos direitos sociais e econômicos, dos direitos das mulheres, do humanitarianismo e do direito internacional para avaliar com mais precisão o que há de novo no idealismo dos direitos humanos no final do século XX. Por outro lado, discutirei quais noções anteriores de direitos humanos internacionais foram substituídas ou superadas nos anos 90, particularmente reinvindicações de direitos coletivos que eram de suma importância para o assim chamado Terceiro Mundo dos anos 1950 a próximo dos anos 1990. Essa 
ironia não reconhecida é que os direitos humanos se tornaram menos, mas mais eurocêntricos nos últimos anos.

Os direitos humanos não são uma nova (e certamente não a última) utopia. Em vez disso, a questão é se o idealismo dos direitos humanos do mundo euroatlântico no final do século XX pode ser visto como utópico de alguma forma. São outros temas que parecem ser novos: a autoevidência dos direitos humanos individuais, que estão acima dos direitos dos Estados; a evocação do sofrimento presente e passado como fonte mobilizadora; e, finalmente, as reivindicações globais conectadas aos direitos humanos como o presentismo da mídia em relação ao fracasso da sua realização, ou seja, a onipresença das crises e o estado de emergência como rotina. O "fim dos tempos dos direitos humanos" (Steven Hopgood) é o aqui e agora global, não um "outro lugar" utópico. Disso se segue, em terceiro lugar, minha conclusão, sugerindo que a ascensão dos direitos humanos como a semântica de crise de um novo fin de siècle pode ser entendido, em parte, como resultado da fratura do regime de tempo moderno, ou seja, das formas em que o passado, o presente e o futuro são refletidos na nossa experiência do tempo. Não é o futuro (ou um passado idealizado) que serve como o ponto de desaparecimento, mas o presente, que se apropria do passado e do futuro para validar o imediato. A nova historiografia dos direitos humanos também pertence, creio eu, a esse contexto. Ela inventa, para a nossa época, uma história dos direitos humanos concebidos como direitos individuais e anteriores ao Estado, que são lidos no passado e futuro como se não houvesse alternativas.

$\mathrm{Na}$ introdução às suas palestras sobre a história da era revolucionária (1868), Jacob Burckhardt usou uma metáfora paradoxal para descrever o interesse cognitivo dos historiadores pelo passado imediato: Wir möchten gern die Welle kennen, auf welcher wir im Ozean treiben, allein wir sind diese Welle selbst ("Nós amamos conhecer a onda que nos carrega para o oceano, mas nós 
A característica mais importante das experiências de crise é o elemento surpresa, o começo dos eventos. O imprevisível transpira de forma tão repentina que adquire uma interpretação significativa somente em retrospecto. ${ }^{10}$ O que para Burckhardt foi a Revolução Francesa e o seu impacto na história do século XIX é para o nosso tempo a série de eventos que começaram na metade da década de 1980 com o fim das ditaduras da América Latina, o fim do apartheid na África do Sul (1994) e a implosão da União Soviética (1991) e, com isso, o fim da Guerra Fria, que havia determinado a política internacional desde o fim do nazismo e dos impérios.

Talvez seja tentador remontar a crise dos regimes autoritários do último terço do século $X X$ à subversão moral através de ideias e movimentos dos direitos humanos, assim como Reinhart Koselleck interpretou a crise do Ancien Régime do último terço do século XVIII como a moralização da política pela filosofia iluminista e pela sociedade civil. ${ }^{11}$ A crítica precedeu a crise. A maior parte das histórias recentes dos direitos humanos argumenta de forma similar. As agitações políticas em torno de 1989, inclusive fora da Europa, são vistas como o resultado de revoluções globais dos direitos humanos, que

\footnotetext{
9 Jacob Burckhardt, Geschichte des Revolutionszeitalters, Werke: kritische Gesamtausgabe, xxviii, ed. Wolfgang Hardtwig et al. (Munich, 2009), 8.

10 Jacob Burckhardt, 'Die geschichtlichen Crisen', in Jacob Burckhardt, Ästhetik der bildenden Kunst [and] Über das Studium der Geschichte. Mit dem Text der Weltgeschichtliche Betrachtungen in der Fassung von 1905, Werke, x, ed. Peter Ganz (Munich, 2000), 146- 7, 252. Ver também James R. Martin, 'The Theory of Storms: Jacob Burckhardt and the Concept of "Historical Crisis"', Journal of European Studies, xl (2010).

${ }^{11}$ Reinhart Koselleck, Critique and Crisis: Enlightenment and the Pathogenesis of Modern Society (Cambridge, Mass., 1988). Para análises mais complexas sobre os direitos humanos no socialismo de Estado, ver Benjamin Nathans, 'Soviet Rights-Talk in the Post-Stalin Era', in Hoffmann (ed.), Human Rights in the Twentieth Century; Benjamin Nathans, 'The Dictatorship of Reason: Aleksandr Vol'pin and the Idea of Rights under "Developed Socialism"', Slavic Review, Ixvi (2007); Celia Donert, 'Charter 77 and the Roma: Human Rights and Dissent in Socialist Czechoslovakia', in Hoffmann (ed.), Human Rights in the Twentieth Century; Celia Donert, The Rights of the Roma: State Socialism and the 'Gypsy Question' (New York, no prelo); Paul Betts, 'Socialism, Social Rights, and Human Rights: The Case of East Germany', Humanity, iii (2012).
} 
começaram na década de 1970. Entretanto, como mostrarei a seguir, essa é uma atribuição retrospectiva apenas parcialmente precisa.

A distinção introduzida por Moyn entre direitos de cidadania (ou direitos do homem) por um lado, e direitos humanos transnacionais, por outro lado, identifica o que é decididamente novo sobre o idealismo dos direitos humanos no final do século XX. Nas revoluções do final do século XVIII e do século XIX, os direitos humanos estavam intimamente ligados à ideia de soberania ou, de forma mais geral, à participação política em um governo democraticamente constituído. Os direitos de cidadania e os direitos humanos eram uma coisa só, e ambos pertenciam ao Estado-nação. Isto também se observou, sem dúvida, no surgimento dos direitos humanos após a Segunda Guerra Mundial e a dissolução dos impérios coloniais, o que provocou uma expansão global sem precedentes de Estados-nações. Os direitos humanos foram frequentemente evocados por nacionalistas africanos em sua luta contra o colonialismo e pela autodeterminação no final da década de 1940, mas também, inicialmente, em protestos contra o racismo e subordinação afro-americana nos Estados Unidos. ${ }^{12}$ Durante a Guerra Fria, os direitos humanos se desenvolveram em uma linguagem da comunidade internacional de Estados e suas organizações, mas foi uma linguagem legal e diplomática utilizada sobretudo em conferências a portas fechadas, e portanto com consequências políticas limitadas. Entre o fim da Segunda Guerra Mundial e o começo dos anos 1990, não houve uma única política humanitária ou intervenção militar que fosse justificada através dos direitos humanos. As poucas intervenções militares que acabaram com políticas genocidas nas décadas depois de 1945 - em Uganda, no Camboja e

\footnotetext{
12 Ver, por exemplo, Andreas Eckert, 'African Nationalists and Human Rights, 1940s-1970s', and Fabian Klose, "Source of Embarrassment": Human Rights, State of Emergency, and the Wars of the Decolonization', both in Hoffmann (ed.), Human Rights in the Twentieth Century; Carol Anderson, Eyes off the Prize: The United Nations and the African American Struggle for Human Rights, 1944-1955 (Cambridge, 2003). Nas Nações Unidas, Libéria e Jamaica foram quem mais pressionou para que questões de raça e religião fossem as principais preocupações dos direitos humanos nos anos 1960: ver Steven L. B. Jensen, The Making of International Human Rights: The 1960s, Decolonization, and the Reconstruction of Global Values (New York, 2016).
} 
Paquistão/Bangladesh - foram conduzidas por Estados-nações vizinhos (Tanzânia, Vietnã e Índia) por questões de realpolitik. Em muitos sentidos, a inviolabilidade da soberania estatal era o pressuposto para que os direitos humanos fossem expansivamente codificados em acordos e tratados internacionais, um processo frequentemente levado adiante pelos novos Estados pós-coloniais, para os quais o direito à autodeterminação era (paradoxalmente apenas em aparência) a base mais importante dos direitos humanos.

Paralelamente ao aumento da codificação internacional dos direitos humanos e sua expansão nas décadas de 1960, 1970 e 1980 em direção a continuamente novos direitos coletivos (por exemplo, o "direito ao desenvolvimento", adotado pela ONU em 1986 e amplamente esquecido atualmente), alguns governos e organizações não governamentais ocidentais começaram, nos anos 70, a descobrir os direitos humanos individuais como uma critério moral para um novo engajamento global para além do Estado-nação. Especialmente nos Estados Unidos, os direitos humanos se tornaram a força motriz de organizações não-governamentais como a Anistia Internacional e o Observatório de Direitos Humanos, mas também para as novas proclamações de política externa eticamente fundamentadas do governo Carter, e depois, com a intensificação da retórica da Guerra Fria, do governo conservador de Reagan. ${ }^{13}$ Além de uma elevação de tom em relação a Estados socialistas e da desvalorização dos direitos humanos sociais e econômicos (que eram apoiados principalmente pelas “Nações Unidas do terceiro mundo”), essa invocação dos direitos humanos ainda não tinha consequências políticas significativas. Os

\footnotetext{
${ }^{13}$ Barbara J. Keys, Reclaiming American Virtue: The Human Rights Revolution of the 1970 s (Cambridge, Mass., 2014); Daniel J. Sargent, A Superpower Transformed: The Remaking of American Foreign Relations in the 1970s (Oxford, 2015); William Michael Schmidli, The Fate of Freedom Elsewhere: Human Rights and the US Cold War Policy toward Argentina (Ithaca, 2013); Sarah B. Snyder, Human Rights Activism and the End of the Cold War: A Transnational History of the Helsinki Network (New York, 2011); Akira Iriye, Petra Goedde and William I. Hitchcock (eds.), The Human Rights Revolution: An International History (Oxford, 2012); Michael Cotey Morgan, 'The Seventies and the Rebirth of Human Rights', in Niall Ferguson et al. (eds.), The Shock of the Global: The 1970s in Perspective (Cambridge, Mass., 2010). Comparar também a análise mais crítica de Greg Grandin, 'The Liberal Tradition in the Americas: Rights, Sovereignty, and the Origins of Liberal Multilateralism', American Historical Review, cxvii (2012).
} 
Estados Unidos continuaram a apoiar financeira e militarmente ditaduras autoritárias na América Latina (incluindo a guerra secreta contra os sandinistas na Nicarágua), assim como insurgências contra a influência soviética, por exemplo, pelos jihadistas islâmicos no Afeganistão.

A popularidade da Anistia Internacional ainda era limitada nesse período; as demandas globais não devem diminuir o fato de que a Anistia tinha sedes organizacionais essencialmente só na Grã-Bretanha, nos Estados Unidos, na Holanda e na Alemanha Ocidental, e seus membros estavam, em sua maioria, satisfeitos em pagar sua adesão como membros. O Observatório de Direitos Humanos foi sempre uma organização de elite de um pequeno grupo de especialistas profissionais (principalmente advogados, pesquisadores e jornalistas, mas não "ativistas") financiados por doações indivíduos ricos. ${ }^{14}$ A retórica da Anistia e dos "direitos humanos" foi, sem dúvida, importante na luta contra o autoritarismo na América Latina, mas o movimento de solidariedade transnacional depois do golpe contra Allende no Chile em 1973, por exemplo, foi muito mais complexo e incluiu noções concorrentes (marxistas, católicas) do que essa solidariedade acarretava. ${ }^{15}$ Certamente, "solidariedade" também foi o termo chave utilizado pelo internacionalismo socialista na década de 1960 e 1970 para conectar os chamados Segundo e Terceiro Mundo na luta contra o racismo e o "imperialismo" norte-americano na América Latina, sul da África e sudoeste asiático - uma imaginação moral global passada cuja história ainda está por ser escrita. ${ }^{16}$ A linguagem dos direitos humanos em si ainda era capaz de ampliação e estava em movimento nos anos 1970, e podia ser invocada por liberais, socialistas ou

\footnotetext{
${ }^{14}$ Cmiel, 'Emergence of Human Rights Politics in the United States', 1243.

15 Patrick Kelly, Latin America and the Making of Global Human Rights (Cambridge, no prelo); Vania Markarian, Left in Transformation: Uruguayan Exiles and the Latin American Human Rights Networks, 1967-1984 (New York, 2005); Jessica Stites Mor (ed.), Human Rights and Transnational Solidarity in Cold War Latin America (Madison, 2013). Acerca do movimento transnacional anti-apartheid: Simon Stevens, 'Why South Africa? The Politics of Anti-Apartheid Activism in Britain in the Long 1970s', in Eckel and Moyn (eds.), Breakthrough.

${ }^{16}$ Como pontos de partida, ver Quinn Slobodian (ed.), Comrades of Color: East Germany in the Cold War World (New York, 2015); Anne E. Gorsuch, “Cuba, My Love”: The Romance of Revolutionary Cuba in the Soviet Sixties', American Historical Review, cxx (2015); James Mark and Péter Apor, 'Socialism Goes Global: Decolonization and the Making of a New Culture of Internationalism in Socialist Hungary, 1956-1989', Journal of Modern History, Ixxxvii (2015); the research project Socialism Goes Global,5http://socialismgoesglobal.exeter.ac.uk4(accessed 6 Mar. 2016).
} 
personalistas, a favor ou (com mais frequência) contra o engajamento dos EUA na região. Também é importante notar que os movimentos sociais transnacionais de massa nos anos 1970 e 1980 não eram organizações não governamentais transnacionais como a Anistia ou o Observatório Internacional, mas o movimento ecológico (do qual também partidos políticos independentes surgiram), o movimento feminista e especialmente os movimentos pacifista e antinuclear. Em outubro de 1981, para lembrarmos apenas um exemplo, milhões protestaram em Bonn, Bruxelas, Paris, Londres e em várias cidades italianas contra a retomada por parte da OTAN da corrida armamentista nuclear contra a União Soviética. ${ }^{17}$ Para esses ativistas pacifistas, o fim anticlimático da Guerra Fria apenas alguns anos depois foi tão surpreendente quanto a onda de intervencionismo de direitos humanos logo após.

Seria igualmente impreciso enxergar os eventos ao redor de 1990 como resultado da "descoberta" dos direitos humanos nos anos 1970. Os eventos da Europa central-oriental (mas também o fim do apartheid na África do Sul e os protestos na China) foram, primeira e mais importantemente, revoluções democráticas focadas em direitos civis e políticos clássicos, mas também sociais e econômicos, além da reafirmação da soberania nacional. O Solidariedade não era uma organização não-governamental de direitos humanos que coletava doações para um sofrimento distante, mas um sindicato que exigia direitos de cidadania no seu país, além de direitos trabalhistas específicos, que atingiu as reivindicações de legitimidade comunista - tão fortes quanto os laços de união entre o catolicismo polonês e o nacionalismo. A solidariedade, portanto, podia ser invocada no ocidente por políticos belicistas neoconservadores em razão do seu anticomunismo, por românticos esquerdistas graças à sua ênfase na autoorganização dos trabalhadores, e por intelectuais liberais em virtude do seu suposto acolhimento à "sociedade civil". ${ }^{18}$

\footnotetext{
${ }_{17}$ Ver, por exemplo, Benjamin Ziemann (ed.), Peace Movements in Western Europe, Japan and the USA during the Cold War (Oxford, 2007).

18 Esse argumento foi desenvolvido por Robert Brier, A Contested Icon: Poland's Solidarity Movement and International Human Rights Culture (a ser publicado).
} 
O mesmo poderia aplicar-se à África do Sul: apesar de Nelson Mandela ter-se tornado um ícone global dos direitos humanos no final dos anos 1980, o Congresso Nacional Africano era um movimento de liberação anticolonial com fortes laços comunistas. O movimento transnacional contra o apartheid já havia começado no final dos anos 1950: sua agenda antirracista era popular entre sindicalistas e protestantes em ambos os lados da cortina de ferro através dos anos 1960 e 1970, e direcionado principalmente contra as políticas do Reino Unido, Estados Unidos e Alemanha, que apoiavam o regime do apartheid. Por mais significativos que tenham sido os shows em apoio a Nelson Mandela em 1988 e 1990 ao conectar a cultura jovem global à causa anti-apartheid, muito mais importantes foram os desdobramentos sociais, políticos e econômicos dentro da África do Sul e o fim dos conflitos de legitimidade da guerra fria em países vizinhos, como Angola, Moçambique e Zimbábue. A Namíbia se tornou independente em 1990; os últimos mercenários cubanos deixaram Angola em 1991. ${ }^{19}$ Os protestos na Praça da Paz Celestial, em 1989, foram conduzidos por estudantes radicais que exigiam minzhu, isto é, "democracia", literalmente "governo do povo", respeito aos direitos dos cidadãos, garantidos pela constituição chinesa, o direito a formar sindicatos e, de forma mais geral, uma renovação no espírito do movimento revolucionário estudantil de 1919. Os protestos também foram, de forma polêmica, direcionados contra o estranho acolhimento do neoliberalismo econômico (e a corrupção governamental) pelas recentes elites comunistas, que começavam a transformar a sociedade chinesa nos anos 1980, sendo um sinal de desdobramentos semelhantes na União Soviética nos anos 1990. ${ }^{20}$

Entretanto, pode-se avaliar o significado dos movimentos caracterizados por protestos democráticos na Europa centro-oriental e, por exemplo, ver a falência

\footnotetext{
19 Comparar Håkan Thörn, Anti-Apartheid and the Emergence of Global Civil Society (Basingstoke, 2006), com as análises muito mais sóbrias em Saul Dubow, Apartheid, 1948-1994 (Oxford, 2014); Sue Onslow (ed.), Cold War in Southern Africa: White Power, Black Liberation (London, 2009).

${ }^{20}$ Ver, por exemplo, o documentário sobre o Protesto na Praça da Paz Celestial de 1989, intitulado The Gate of Heavenly Peace (1995) produzido por Richard Gordon e Carma Hinton: https://www.youtube.com/watch?v 1Gtt2JxmQtg4 (último acesso em 6 de março de 2015).
} 

"constelação pós-nacional" ou algum tipo de "sociedade civil global". ${ }^{21}$ Ao contrário, esse retorno à soberania nacional apareceu aos atores políticos (semelhantemente aos momentos de pós-guerra em 1918 e 1945) como a única garantia para as reivindicações de direitos e para a participação política, como ilustrado pela mudança na retórica dos movimentos democráticos de massa na Alemanha oriental, desde o Wir sind das Volk ("Nós somos o povo") até o Wir sind ein Volk ("Nós somos um povo"); essa mudança aconteceu simultaneamente em outros Estados ex-socialistas da Europa oriental. ${ }^{22} \mathrm{~A}$ união das reivindicações de direitos com as reivindicações de soberania levou não só à implosão do comunismo, como também ao colapso das federações socialistas multiétnicas (na União Soviética, mas também na Tchecoslováquia e lugoslávia), com consequências dramáticas, especialmente nos Bálcãs.

Os direitos humanos não foram os catalisadores decisivos dessas revoluções, crises e guerras, e, portanto, do colapso de uma velha ordem internacional e do surgimento de uma nova, mas se fizeram correntes como resposta a esses eventos. Em muitos sentidos, a reorganização do mundo na sequência dos eventos de 1989-91 lembrou os acordos internacionais anteriores de 1918 e 1945. Assim como após a Primeira e a Segunda Guerra Mundial, a cadeia de eventos posterior ao fim da Guerra Fria também foi marcada, por um lado, pela simultaneidade da implosão de impérios, a erupção de guerras civis étnicas, a divisão de Estados e as consequentes

\footnotetext{
21 Jürgen Habermas, The Postnational Constellation: Political Essays (Cambridge, 2001); John Keane, Global Civil Society? (Cambridge, 2003). Ver Liisa Malkki para uma primeira crítica, 'Things to Come: Internationalism and Global Solidarities in the Late 1990s', Public Culture, x (1998).

${ }^{22}$ Charles S. Maier, Dissolution: The Crisis of Communism and the End of East Germany (Princeton, 1997); James Krapfl, Revolution with a Human Face: Politics, Culture, and Community in Czechoslovakia, 19891992 (Ithaca, 2013); Michal Kopeček, "Human Rights Facing a National Past: Dissident "Civic Patriotism" and the Return of History in East Central Europe, 1968-1989', Geschichte und Gesellschaft, xxxviii (2012); Stephen Kotkin, com a contribuição de Jan T. Gross, Uncivil Society: 1989 and the Implosion of the Communist Establishment (New York, 2009); Stephen Kotkin, Armageddon Averted: The Soviet Collapse, 1970-2000 (Oxford, 2001).
} 
crises de refugiados e limpezas étnicas, e, por outro lado, pela promessa de participação democrática e por visões elevadas de uma nova ordem internacional, mais justa e pacífica. ${ }^{23} \mathrm{O}$ que aconteceu foi que o idealismo dos direitos humanos dos anos 1990 se distinguiu dos dois períodos de pós-guerra anteriores pelo fato de que a invocação à soberania nacional, pelo menos na Europa ocidental (ao contrário do leste europeu), era percebida como um assunto passado. Nesse sentido, o liberalismo normativo dos anos 1990, especialmente de neokantianos como Jürgen Habermas, também foi além do liberalismo iluminista do final do século XVIII e século XIX, que, para a surpresa de muitos, ressurgiu repentinamente em todos os outros sentidos. ${ }^{24}$

Enquanto que para Kant e acadêmicos liberais internacionais da área do direito do século XIX, o ethos cosmopolita era fundamentado na sociedade de Estados e seus interesses de poder legítimos, para Habermas e outros intelectuais ocidentais o Estado-nação era o maior impedimento para uma democracia global cosmopolita que devia ser baseada nos direitos humanos; e as agitações políticas na Europa central e oriental nos anos 1990 eram meramente uma revolução retificadora (nachholende Revolution) que implementou o que o ocidente havia há muito atingido: democracia, soberania nacional, economia de mercado, direitos civis garantidos por um Estado constitucional. (Em seus escritos, entretanto, o próprio Habermas não desenvolveu o conceito de "direitos humanos" até 1992 em Faktizität und Geltung.)25 Seguindo Martti Koskenniemi, podemos falar de uma "virada ética" ao longo dos anos 1990 na filosofia e na sociologia política, mas também no direito internacional e (como será mostrado em breve) na política internacional, com direitos humanos individuais

\footnotetext{
${ }^{23}$ Eric D. Weitz, 'From the Vienna to the Paris System: International Politics and the Entangled Histories of Human Rights, Forced Deportations, and Civilizing Missions', American Historical Review, cxiii (2008); Erez Manela, The Wilsonian Moment: Self-Determination and the International Origins of Anticolonial Nationalism (New York, 2007); Mark Mazower, 'The Strange Triumph of Human Rights, 1933-1950', Historical Journal, xlvii (2004).

${ }^{24}$ Emma Rothschild, 'What Is Security?', Daedalus, cxxiv, 3 (1995), 54.

25 Jürgen Habermas, Faktizität und Geltung: Beiträge zur Diskurstheorie des Rechts und des demokratischen Rechtsstaats (Frankfurt, 1992), trad. William Rehg as Between Facts and Norms: Contributions to a Discourse Theory of Law and Democracy (Cambridge, Mass., 1996).
} 
vistos como ideia regulatória. ${ }^{26}$ Os direitos humanos se tornaram, portanto, a promessa que os eventos em torno de 1990 adquiririam significado histórico. Repentinamente, os direitos humanos se tornaram tão autoevidentes quanto os mercados desregulados durante os "estrondosos anos 90": de acordo com o título levemente irônico do bestseller de Joseph Stiglitz, "a década mais próspera do mundo". ${ }^{27}$ E esta era uma versão particular dos direitos humanos, pré-Estado e individuais, que se estabeleceu cada vez mais nos anos 1990 e cuja história foi, por assim dizer, inventada.

Para avaliar quão rapidamente essa transformação "ética" no mundo pós-Guerra Fria ocorreu, lembremos dois conflitos militares, um que aconteceu no começo da década e outro ao seu final: a guerra do Iraque em 1990-91 e a guerra do Kosovo em 1998-99. A primeira guerra do Iraque, que começou em setembro de 1990 com a invasão de Saddam Hussein ao Kuwait, foi a primeira guerra após o término da Guerra Fria. Em contraste com os conflitos durante a Guerra Fria, da Coreia ao Afeganistão, esta não foi uma guerra por procuração entre dois superpoderes. Os Estados Unidos lideraram uma coalização multilateral contra o Iraque, sancionada pelas Nações Unidas após a soberania de um de seus Estados membros ter sido violada. Essa foi uma justificativa imediata dada para a intervenção, além de interesses econômicos claramente identificados (particularmente o controle sobre a estabilidade do fornecimento de petróleo), mas não as políticas genocidas de Saddam Hussein contra os curdos, como o uso de armas químicas na população civil curda em Halabja em 1988 (assim como Jimmy Carter, durante sua breve acolhida retórica dos direitos humanos no final dos anos 1970, não fez nada a respeito do genocídio realizado pelo

\footnotetext{
${ }^{26}$ Martti Koskenniemi, “"The Lady Doth Protest Too Much”: Kosovo and the Turn to Ethics in International Law”, Modern Law Review, Ixv (2002). Ver também Paul W. Kahn, “Speaking Lawto Power": Popular Sovereignty, Human Rights, and the New Intemational Order, Chicago Journal of International Law, i (2000); David Chandler, From Kosovo to Kabul and Beyond: Human Rights and International Intervention (London, 2006).

27 Joseph E. Stiglitz, The Roaring Nineties: A New History of the World's Most Prosperous Decade (New York, 2004). Ver também Alasdair Roberts, The Logic of Discipline: Global Capitalism and the Architecture of Government (Oxford, 2010). Para uma das interpretações históricas dos anos 90 na Europa, ver Philipp Ther, Die neue Ordnung auf dem alten Kontinent: eine Geschichte des neoliberalen Europa (Berlin, 2014). Sobre a posição da África no mundo pós-Guerra Fria, ver, particularmente, James Ferguson, Global Shadows: Africa in the Neoliberal World Order (Durham, NC, 2006).
} 
ocidental, que permitiu uma conduta de guerra que diminuiu muito as suas baixas. Também foi a primeira guerra a ser transmitida ao vivo pela televisão (o chamado "efeito (NN"), o que levou a enormes protestos a favor da paz com centenas de milhares de participantes na Europa ocidental e em outros locais, sendo a última manifestação do movimento pacifista internacional.

A guerra do Kosovo contra a lugoslávia de Slobodan Milošević continuou esses dois últimos acontecimentos. Foi uma guerra conduzida pelos ares sem perdas humanas para o ocidente, mas com muitas baixas de civis (o chamado "dano colateral", um neologismo dos anos 1990, juntamente com o termo "estados vilões"), e na qual as imagens teriam um papel fundamental. Em outros aspectos, entretanto, foi uma guerra fundamentalmente diferente da primeira guerra do Iraque. O envio de tropas ao Kosovo foi a primeira guerra a ser conduzida pela OTAN. Foi uma guerra iniciada sem a aprovação das Nações Unidas, contra um de seus Estados membros, estando, portanto, fora do direito internacional. E, finalmente, foi a primeira guerra travada em nome dos direitos humanos a fim de impedir um genocídio. Chamada de "intervenção humanitária", a guerra do Kosovo se tornou o laboratório para as guerras lideradas pelos Estados Unidos (e pela Grã-Bretanha de Tony Blair) após o 11 de Setembro. O reenquadramento dos Estados Unidos como um superpoder moral relutante, purificado de seus pecados da Guerra Fria na Indochina e na América Latina, mas hesitante demais em combater o mal genocida no mundo, é essencialmente uma invenção da segunda metade dos anos $1990 .^{28}$

\footnotetext{
${ }^{28}$ Um caso digno de nota é o de Samantha Power, que começou como uma jovem jornalista americana durante a guerra civil na antiga lugoslávia e, primeiro como uma acadêmica dos direitos humanos em Harvard e depois como consultora de política externa, se tornou uma das defensoras mais proeminentes do intervencionismo americano: Samantha Power, A Problem from Hell: America and the Age of Genocide (New York, 2002). De forma semelhante, ver Gary J. Bass, Freedom's Battle: The Origins of Humanitarian Intervention (New York, 2008). Contrastar com Stephen Wertheim, 'A Solution from Hell: The United States and the Rise of Humanitarian Interventionism, 1991-2003', Journal of Genocide Research, xii (2010).
} 
A reação exagerada do ocidente (principalmente da Europa ocidental) à guerra do Kosovo só pode ser explicada pela hesitação prolongada da União Europeia e dos Estados Unidos em intervir na dissolução sangrenta da lugoslávia (além das fracassadas intervenções anteriores e da relutância em intervir em outras catástrofes humanitárias dos anos 1990 na Somália, na Ruanda, e no Timor Leste). O colapso econômico dos anos 1980, acelerado por reformas para acomodar os empréstimos do Banco Mundial e do Fundo Monetário Internacional, além do final da Guerra Fria, e portanto a possibilidade de estabelecer novos Estados-nações na Europa (evidente no exemplo da reunificação da Alemanha), contribuíram para a desintegração da federação iugoslava multiétnica na sequência da morte de Tito. (Nos anos 1960 e 1970, a lugoslávia socialista era uma das sociedades industriais mais desenvolvidas do mundo e um modelo para muitos Estados não-alinhados.) As regiões econômicas mais potentes, Eslovênia e Croácia, se declararam nações soberanas (com o apoio do ocidente) e portanto transformaram as populações sérvias dentro desses novos Estados-nações em minorias étnicas com direitos de cidadania limitados. Assim continuou uma espiral de violência, levada adiante principalmente pelas tentativas de antigos quadros comunistas de se manterem no poder, em primeiro lugar e sobretudo Milošević, que invocou a questão étnico-nacionalista e, ao mesmo tempo, a ideologia socialista de "fraternidade e união" das nações e minorias iugoslavas. O ocidente viu na consequente guerra civil um retorno atávico ao ódio étnico que havia sido ostensivamente reprimido na lugoslávia socialista, e inicialmente não quis se envolver. O ponto de inflexão veio somente com a guerra civil na Bósnia-Herzegovina de 1992 a 1995 e estava principalmente conectado, simbolicamente e na mídia global, com dois eventos: o cerco de Sarajevo, de 1992 ao começo de 1996, e o massacre em Srebrenica em julho de 1995, no qual aproximadamente 8000 homens e meninos muçulmanos foram mortos por paramilitares sérvios. 
Como no ano anterior em Ruanda, esse massacre aconteceu diante de pacificadores das Nações Unidas - uma expressão do fracasso político das Nações Unidas e, portanto, o fim de esperanças depositadas na organização de que ela se tornaria uma espécie de governo mundial. (Em 1992, Boutros Boutros-Ghali, o primeiro secretário-geral africano da ONU, havia afirmado que, após o fim da Guerra Fria, a hora das Nações Unidas e da sua Carta tinha finalmente chegado). ${ }^{29} \mathrm{E}$ semelhantemente em relação à União Europeia, para qual havia altas esperanças após 1990. Entretanto, ela também não estava em condições de conter o conflito na lugoslávia, sobretudo porque os europeus queriam continuar a acreditar que as guerras civis por questões de soberania haviam ficado no passado. E mesmo os Estados Unidos sob a nova administração Clinton, após a experiência desastrosa na Somália em 1992, não quis se envolver, inicialmente, em um conflito sem interesses geopolíticos claros.

Uma das respostas do fracasso político das instituições internacionais nessas guerras civis violentas e catastróficas foi a adoção tardia da ideia de intervencionismo de direitos humanos pela geração dos baby boomers e por manifestantes estudantis como Bill Clinton e, posteriormente, Tony Blair, Bernard Kouchner e Joschka Fischer, que haviam chegado ao poder em 1990.30 Crucial para esse avanço do idealismo dos direitos humanos foi sua conexão com a lembrança do Holocausto, que também teve seu auge nos anos 1990, e com a acusação de genocídio que fez de Srebrenica um segundo Auschwitz. Precisamente essa conexão entre direitos humanos e genocídio -

\footnotetext{
${ }^{29}$ Secretário-geral do Conselho de Segurança, 'An Agenda for Peace: Preventive Diplomacy, Peacemaking and Peacekeeping', 17 de junho 1992, 5 http://www.un.org/ en/sc/repertoire/89-92/Chapter\%208/GENERAL\%20ISSUES/Item\%2029_Agen da\%2ofor\%2opeace_.pdf4 (acesso em 06 de março de 2016).

${ }^{30}$ Sobre a trajetória intelectual dessa geração, ver principalmente a obra de Paul Berman, A Tale of Two Utopias: The Political Journey of the Generation of 1968 (New York, 1996); Julian Bourg, From Revolution to Ethics: May 1968 and Contemporary French Thought (Montreal, 2007); Richard Wolin, 'From the "Death of Man" to Human Rights: The Paradigm Change in French Intellectual Life, 1968-1986', in Mark Bevir, Jill Hargis and Sara Rushing (eds.), Histories of Postmodernism (New York, 2007); Robert Horvath, “The Solzhenitsyn Effect”: East European Dissidents and the Demise of the Revolutionary Privilege', Human Rights Quarterly, xxix (2007); Kristin Ross, 'Ethics and the Rearmament of Imperialism: The French Case', in Wasserstrom et al. (eds.), Human Rights and Revolutions.
} 
na declaração. De modo inverso, os direitos humanos não foram mencionados de nenhum modo na Convenção para a Prevenção e para a Repressão do crime de genocídio, adotada no mesmo ano. Pelo fato de a definição de genocídio de Raphael Lemkin ser direcionada de forma muito restrita à intenção particular dos nazistas de exterminar populações inteiras, a convenção se mostrou amplamente inadequada para a mobilização internacional contra a violência em massa que fazia parte das guerras civis étnicas e religiosas antes dos anos 1990. ${ }^{31}$

Foi o aspecto da guerra civil na Bósnia que lembrava os campos de concentração - no coração da Europa, como muitos comentaristas contemporâneos enfatizaram, e não em Ruanda ou logo depois no sangrento e longo conflito civil no Congo (com mais de 5 milhões de vítimas) - que provocou uma reviravolta para uma política ocidental intervencionista em nome dos direitos humanos. Intelectuais ocidentais midiáticos como André Glucksman, Alain Finkielkraut, Bernard-Henri Lévy e Susan Sontag fizeram peregrinações a Sarajevo e anunciaram que estariam lá para impedir outro Auschwitz, enquanto governos ocidentais, mais uma vez, pareciam estar apenas assistindo (como fizeram no final dos anos 1930 e começo dos anos 1940). ${ }^{32}$

O conflito no Kosovo cinco anos depois se tornou assim o primeiro caso de teste para a nova crença na intervenção militar em nome dos direitos humanos. No Kosovo, a conexão com acusações de genocídio, que hoje

\footnotetext{
${ }^{31}$ A. Dirk Moses, Genocide and the Terror of History: The Quest for Permanent Security (Cambridge, no prelo); A. Dirk Moses, 'Raphael Lemkin, Culture, and the Concept of Genocide', in Donald Bloxham and A. Dirk Moses (eds.), The Oxford Handbook of Genocide Studies (Oxford, 2010). Ver também Anson Rabinbach, 'Genozid: Genese eines Konzepts', in Anson Rabinbach, Begriffe aus dem Kalten Krieg: Totalitarismus, Antifaschismus, Genozid (Göttingen, 2009); Lasse Heerten, " " $A$ " as in Auschwitz, "B" as in Biafra: The Nigerian Civil War, Visual Narratives of Genocide, and the Fragmented Universalization of the Holocaust', in Heide Fehrenbach and Davide Rodogno (eds.), Humanitarian Photography: A History (Cambridge, 2015).

32 Richard J. Golsan, Vichy's Afterlife: History and Counter-History in Postwar France (Lincoln, Nebr., 2000), especialmente o capítulo 8. Para uma primeira crítica da percepção distorcida dos problemas do leste e sudeste europeus por intelectuais franceses, ver Tony Judt, 'Paris and the Tribes of Europe', French Politics and Society, x (1992).
} 
fazem parte do repertório padrão de conflitos militares, da Síria à Ucrânia, motivou a ação política pela primeira vez. Nas palavras de Susan Sontag, "Há maldade radical no mundo, e é por isso que há guerras justas. E esta é uma guerra justa. Mesmo que tenha sido canhestra. Chega de genocídio". 33 Em muitos sentidos, entretanto, a acusação de genocídio não compreende a natureza do conflito no Kosovo, como já apontavam jornalistas bem informados na época. ${ }^{34} \mathrm{O}$ Exército de Libertação do Kosovo, equipado com o arsenal da colapsada Albânia comunista, liderou uma guerra de guerrilha contra o Exército do Povo da lugoslávia na província do Kosovo e explorou a lógica de guerra de civil de escalada de terror e retaliação a fim de convencer o ocidente de que Milošević planejava cometer um genocídio contra os albaneses do Kosovo. Em contraste com a sua abordagem na guerra da Bósnia, a OTAN não se limitou, nesse caso, a demonstrações simbólicas de poder, mas decidiu declarar guerra à lugoslávia. A OTAN interveio na guerra civil com ataques aéreos, começando assim (como ficou claro retrospectivamente) uma catástrofe humanitária no Kosovo. Por mais justificada que possa parecer a intervenção militar em 1999, aqui eu estou preocupado somente com o fraseado de sua justificativa. A Guerra do Kosovo marcou o começo de uma nova era de intervenções humanitárias e militares com base em genocídios ostensivos e violações dos direitos humanos. 35

\section{II}

Os temas mais importantes para o novo idealismo dos direitos humanos podem ser encontrados nas justificativas da guerra do Kosovo: a proeminência dos direitos humanos individuais acima dos direitos dos Estados; referência às políticas genocidas da Segunda Guerra Mundial (mas

\footnotetext{
33 Susan Sontag, 'Why Are We In Kosovo?', New York Times, 2 May 1999.

34 For example, Tim Judah, Kosovo: War and Revenge (New Haven, 2000).

35 Mariella Pandolfi, 'Laboratory of Intervention: The Humanitarian Governance of the Postcommunist Balkan Territories', in Mary-Jo DelVecchio Good et al. (eds.), Postcolonial Disorders (Berkeley and Los Angeles, 2008).
} 
não, por exemplo, às atrocidades coloniais europeias ou às guerras por procuração da Guerra Fria, ou seja, à história do intervencionismo nos séculos XIX e XX); reivindicações globais de direitos humanos e o estado de emergência humanitário que, transmitido na mídia, exige respostas aqui e agora (e não no futuro distante).

Mas esses temas eram realmente novos e utópicos? Como a "virada ética" no direito e na política internacionais fez o conflito do Kosovo aparentar ser diferente, por exemplo, da guerra no Biafra de trinta anos antes? Dois exemplos podem ser suficientes. Em 29 de abril de 1999, um mês após a ação militar da OTAN no Kosovo começar, Jürgen Habermas publicou um artigo no jornal alemão Die Zeit intitulado Humanität und Bestialität ("Humanidade e Bestialidade"). No artigo, Habermas designou a agenda da guerra do Kosovo como uma "transformação do direito internacional em um direito de cidadãos globais". O filósofo alemão escreveu acerca de uma "'operação policial' que a OTAN generosamente desempenha para a comunidade internacional" contra Estados "que insistiram neuroticamente na sua soberania". No artigo (e no livro subsequente) ele identificou o dilema da política dos direitos humanos como tendo que agir como se uma sociedade civil global totalmente institucionalizada já existisse, mesmo que a sua própria promoção fosse o objetivo da ação militar. A guerra, portanto, Ihe parecia estar "no limite entre a legalidade e a moralidade". Ainda assim, na guerra do Kosovo, Habermas viu a confirmação do kantismo normativo que ele usara nos anos 1990 para argumentar a favor de uma lei cosmopolita que estivesse acima e além dos direitos dos Estados e que pudesse substituir, finalmente, a força bruta da política de poder. ${ }^{36}$

Exatamente no mesmo dia que o artigo de Habermas foi publicado, Vaclav Havel argumentou de forma similar no Senado e no Câmara dos Comuns canadenses, em um conceituado discurso intitulado "Kosovo e o Fim

\footnotetext{
36 Jürgen Habermas, 'Bestialität und Humanität: ein Krieg an der Grenze zwischen Recht und Moral', Die Zeit, 29 Apr. 1999, traduzido como 'Bestiality and Humanity: A War on the Border between Legality and Morality', Constellations, vi (1999); Jürgen Habermas, Der gespaltene Westen: kleine politische Schriften X (Frankfurt, 2004).
} 
do Estado-nação". O presidente da República Tcheca e antigo dissidente afirmou que a OTAN conduzia uma guerra contra um regime genocida:

Esta é provavelmente a primeira guerra que não foi travada em nome do "interesse nacional", mas em nome de princípios e valores. Se é possível dizer que alguma guerra é ética, ou que oi travada por motivos éticos, então isso pode ser dito a respeito desta guerra.

Mais adiante no discurso ele afirmou:

Esta guerra coloca os direitos humanos acima dos direitos do Estado. A República Federativa da lugoslávia foi atacada pela aliança sem um mandato direto das Nações Unidas. Isso não aconteceu de forma irresponsável, como um ato de agressão ou de um desrespeito ao direito internacional. Pelo contrário, aconteceu por respeito ao direito, a um direito que está acima do direito que protege a soberania dos Estados. A aliança agiu por respeito aos direitos humanos, como manda tanto a consciência quanto os documentos legais internacionais. ${ }^{37}$

Em outras palavras, ao final dos anos 1990 temos o "avanço" da nova moralidade global da política dos direitos humanos, que se coloca acima dos direitos dos Estados, que Moyn identifica como tendo acontecido no final dos anos 1970 .

A intervenção da OTAN no Kosovo teria sido inconcebível sem as imagens precedentes dos massacres na Bósnia e em Ruanda. De fato, Kofi Annan, em seu Relatório do Milênio para as Nações Unidas em 2000, se referiria explicitamente a Srebrenica e Ruanda para justificar intervenções humanitárias contra Estados membros soberanos das Nações Unidas. ${ }^{38}$ No Kosovo, não foi primeira e mais importantemente os Estados Unidos que se sentiram obrigados a agir, mas as elites europeias, em particular o governo do partido trabalhista de Londres e a coalizão da socialdemocrata com o Partido Verde de Berlim. Para o Partido Verde alemão e seu ministro de relações exteriores, Joschka Fischer, foi um desafio particular. Afinal, o Partido Verde

37 Václav Havel, 'Kosovo and the End of the Nation-State', New York Review of Books, 10 June 1999.

$3^{8}$ Kofi A. Annan, We the Peoples: The Role of the United Nations in the 21st Century (New York, 2000), 48. 
surgiu dos movimentos pacifistas dos anos 1970 e 1980. Eles agora precisavam se comprometer com imperativos intervencionistas do novo regime global de direitos humanos. Em uma convenção espetacular do Partido Verde, Fischer conseguiu superar uma oposição amarga (e física) e ganhar (usando o argumento "Auschwitz nunca mais") a maioria dos delegados do partido pacifista para a ação militar da OTAN. Somente sua oposição à segunda guerra do Iraque em 2003 e sua memorável interação com o secretário de defesa dos EUA, Donald Rumsfeld, em uma coletiva de imprensa ("Desculpe-me, eu não estou convencido!"), redimiriam Fischer aos olhos de muitos pacifistas do seu partido.

Os anos 1990 também marcaram o começo de uma nova era do processo legal da violência de massa e do genocídio. As guerras civis na antiga lugoslávia e na Ruanda foram novamente os catalizadores cruciais para o surgimento de um novo direito penal internacional e suas instituições, possivelmente a maior realização do direito em termos de direitos humanos das duas décadas desde a Bósnia. Em contraste com o que geralmente se presume, quase todas as convenções e tratados importantes de direitos humanos já haviam sido estabelecidos durante a Guerra Fria, levados adiante principalmente pelos Estados pós-coloniais não-alinhados (por exemplo, o pacto de direitos humanos de 1966). Como observou Anthony Anghie, os acordos não vinculativos de Helsinki de 1975, que ganharam importância na historiografia recente dos direitos humanos, não acrescentaram muito à estrutura criada pelos tratados de 1966.39 A Declaração de Viena adotada pela Conferência Mundial dos Direitos Humanos de 1993, com sua ênfase nos direitos das mulheres, e na indivisibilidade entre direitos civis, sociais, culturais e econômicos, e finalmente o estabelecimento do alto comissariado das Nações Unidas para os direitos humanos, pertence, de diversas formas, a essa primeira estrutura. Simultaneamente, a Conferência de Viena também constituiu o ressurgimento do debate acerca da universalidade dos direitos

\footnotetext{
39 Antony Anghie, 'Whose Utopia? Human Rights, Development, and the Third World', Qui parle, xxii (2013), 70.
} 
humanos, a que certos Estados asiáticos se opuseram com o argumento que os direitos humanos devem estar conectados com o contexto local e com o coletivo. Portanto, o debate sobre os direitos humanos como uma forma de universalismo particularmente ocidental também é resultado da era pósguerra fria: antes, os direitos humanos não eram vistos como incompatíveis com os direitos coletivos. Pelo contrário, nos anos 1950 e 1960, políticos anticolonialistas haviam evocado os direitos humanos na arena internacional contra o colonialismo ocidental. ${ }^{40}$ As convenções e os tratados de direitos humanos dos anos 1960, 1970 e 1980 ainda eram voltados para a promoção da juridificação do mundo com o intuito de tornar os resultados da descolonização (especialmente a autodeterminação política e econômica) irreversíveis e permitir uma distribuição global da riqueza mais justa no futuro. Em contraste, as inovações em leis internacionais de direitos humanos dos anos 1990 se localizaram primeiramente no reino do processo legal - mas também no fato de se ter chegado a um acordo em termos historiográficos, morais e psicológicos - com erros passados.

A Corte Penal Internacional foi estabelecida nesse período, que também marcou o surgimento dos estudos comparativos de genocídios e, de forma mais geral, de uma mudança nas sensibilidades historiográficas, desde a história (progressiva, linear) à memória (catastrófica, cataclísmica) no mundo euro-atlântico. 41 "Trauma", "vitimização" e "testemunho" se tornaram termos chave usados para criar uma nova forma de se reconciliar com o passado, em referência, especificamente, ao Holocausto como o evento a partir do qual os

\footnotetext{
40 Roland Burke, Decolonization and the Evolution of International Human Rights (Philadelphia, 2010). Ver também Sundhya Pahuja, Decolonising International Law: Development, Economic Growth, and the Politics of Universality (Cambridge, 2011); Daniel Roger Maul, Human Rights, Development and Decolonization: The International Labour Organization, 1940-70 (Basingstoke, 2012); Talbot C. Imlay, 'International Socialism and Decolonization during the 1950s: Competing Rights and the Postcolonial Order', American Historical Review, cxviii (2013).

${ }^{41}$ Para críticas sutis, ver principalmente Henri Rousso, The Haunting Past: History, Memory, and Justice in Contemporary France (Philadelphia, 2002); John Torpey, 'The Pursuit of the Past: A Polemical Perspective', in Peter Seixas (ed.), Theorizing Historical Consciousness (Toronto, 2004); John Torpey, Making Whole What Has Been Smashed: On Reparation Politics (Cambridge, Mass., 2006); Robert Meister, After Evil: A Politics of Human Rights (New York, 2012).
} 
direitos humanos supostamente surgiram. ${ }^{42}$ Esta narrativa histórica - direitos humanos como uma resposta ao Holocausto - parece irresistível, conquanto a nova historiografia revisionista insista que não foi o choque causado pelas políticas genocidas nazistas que gerou as normas dos direitos humanos no final dos anos 1940 e 1950.43 Foi o trabalho com um passado distópico de sofrimento humano individual que se acredita ter levado à ação política e moral no presente global. Essa também é a principal narrativa moral para a nova historiografia dos direitos humanos, que se estabeleceu no final dos anos 1990: o sofrimento humano passado paradoxalmente acelera a evolução dos direitos humanos. 44

Novamente, essas narrativas não apontam para uma utopia "em outro lugar". Em vez disso, elas apontam para uma expansão global e temporal do quadro normativo, com a qual especialmente as elites europeias e anglófonas declaram já estar moralmente comprometidas. Em termos legais, os governos dos Estados Unidos tomaram muito cuidado para não cair sob a jurisdição dessa doutrina dos direitos humanos internacionais, e não assinaram, por exemplo, o Estatuto da Corte Penal Internacional de 2002 (Roma), ilustrando, como contestado por críticos, a desigualdade inerente ou a hipocrisia imperial dessa

\footnotetext{
${ }^{42}$ Ver, por exemplo, Daniel Levy e Natan Sznaider, Human Rights and Memory (University Park, 2010). Mais cético é Andreas Huyssen, 'International Human Rights and the Politics of Memory: Limits and Challenges', Criticism, liii (2011).

43 Comparar, por exemplo, G. Daniel Cohen, 'The Holocaust and the "Human Rights Revolution": A Reassessment', in Iriye, Goedde and Hitchcock (eds.), Human Rights Revolution, with Marco Duranti, 'The Holocaust, the Legacy of 1789 and the Birth of International Human Rights Law: Revisiting the Foundation Myth', Journal of Genocide Research, xiv (2012); Marco Duranti, Human Rights and Conservative Politics in Postwar Europe (Oxford, no prelo). De modo semelhante, Moyn, Last Utopia, 82-3; Samuel Moyn, 'The Intersection with Holocaust Memory', in Samuel Moyn, Human Rights and the Uses of History (London, 2014); Samuel Moyn, Christian Human Rights (Philadelphia, 2015).

44 Ver, por exemplo, Paul Gordon Lauren, The Evolution of International Human Rights: Visions Seen (Philadelphia, 1998); Michael Ignatieff, Human Rights as Politics and Idolatry, ed. Amy Gutmann (Princeton, 2001); Micheline R. Ishay, The History of Human Rights: From Ancient Times to the Globalization Era (Berkeley, 2004); Hunt, Inventing Human Rights; Jean H. Quataert, Advocating Dignity: Human Rights Mobilizations and Global Politics (Philadelphia, 2009). Para uma "genealogia afirmativa" das maneiras pelas quais o sofrimento passado se transforma em direitos, ver Hans Joas, Die Sakralität der Person: eine neue Genealogie der Menschenrechte (Frankfurt, 2012), trans. Alex Skinner as The Sacredness of the Person: A New Genealogy of Human Rights (Washington, DC, 2013).
} 
práticas de tortura na prisão de Abu Ghraib no Iraque, a Anistia primeiramente criticou a ação, argumentando que colocava em risco a incipiente prática legal internacional de processar os violadores de baixa e média hierarquia (primeiramente, devo dizer, em países africanos). ${ }^{46} \mathrm{~A}$ queixa contra Rumsfeld foi feita em Paris sob o princípio da jurisdição internacional, já que a França, diferentemente dos Estados Unidos, era um país membro da Corte Penal Internacional. O promotor de Paris acabou não recebendo o caso em 2008, argumentando que Rumsfeld era imune durante o mandato. Assim, a prisão sensacionalista do General Augusto Pinochet em Londres, em 1998, justificada por uma acusação do magistrado espanhol Baltasar Garzón Real por tortura durante a ditadura chilena, continua sendo a exceção, sem repetições, que prova a regra.

O surgimento do direito penal internacional, assim como o surgimento dos direitos humanos individuais em geral, foi acompanhado nos anos 1990 pela criação de um grande número de organizações não-governamentais humanitárias e de direitos humanos. Certamente, o "novo humanitarianismo" já havia surgido no final dos anos 1960 e começo dos anos 70 com as crises de Biafra e Bangladesh, além da fundação dos Médicos sem Fronteiras. ${ }^{47}$ Contudo, na nova era de intervenções depois do fim da Guerra Fria, formas militares e humanitárias de governança fora da lei internacional andam juntas: "O humanitarianismo se

\footnotetext{
45 Mark Mazower, Governing the World: The History of an Idea (London, 2012), 400.

46 Wolfgang Kaleck, Mit zweierlei Maß: der Westen und das Völkerstrafrecht (Berlin, 2012), 77. O Observatório dos Direitos Humanos, dessa vez com ajuda da Anistia, tratou dessas questões no seu relatório "Getting Away with Torture? Command Responsibility for the U.S. Abuse of Detainees', Human Rights Watch, xvii, 1 (2005), https://www.hrw.org/reports/2005/us0405/us0405.pdf4 (último acesso em 5 de março de 2016).

47 Peter Redfield, Life in Crisis: The Ethical Journey of Doctors without Borders (Berkeley, 2013); Eleanor Davey, Idealism beyond Borders: The French Revolutionary Left and the Rise of Humanitarianism, 19541988 (Cambridge, 2015); Lasse Heerten, The Biafran War and Postcolonial Humanitarianism: Spectacles of Suffering (New York, no prelo).
} 
tornou a justificativa para ação extralegal". ${ }^{48}$ A verdadeira interdependência global do mundo e o fluxo de imagens na mídia de notícias e nas redes sociais levam à suposição de uma "emergência imaginária" que desistoriciza as raízes políticas e sociais dos conflitos e requer ação imediata. 49 O processo de reinvindicação de direitos, como o direito de asilo, também passou por uma transformação a partir dos anos 1990: já não se espera que candidatos apresentem histórias de perseguição política (por exemplo, por regimes ditatoriais); em vez disso, eles devem relatar seu processo de trauma e literalmente mostrar as suas feridas, ou seja, documentar o seu sofrimento corpóreo.$^{50} \mathrm{O}$ foco não é a reconstrução social e política dos pedidos de asilo, mas o sofrimento individual e o trauma emocional. A empatia humanitária substitui a reinvindicação de direitos; sujeitos políticos se tornam vítimas traumatizadas.

Uma redefinição semelhante acontece desde os anos 1990 no caso dos direitos das mulheres. Certamente, a violência sexual passou a finalmente ser identificada como um crime contra a humanidade nos tribunais penais internacionais para Ruanda e a antiga lugoslávia. Ao mesmo tempo, "as mulheres foram inscritas, essencialmente, no direito internacional, predominantemente através das suas experiências dolorosas", ou seja, através do seu sofrimento individual. ${ }^{51}$ Ao procurar asilo, as mulheres

\footnotetext{
${ }^{48}$ Didier Fassin e Mariella Pandolfi (eds.), Contemporary States of Emergency: The Politics of Military and Humanitarian Interventions (New York, 2010), 13 (introdução dos editores).

49 Craig Calhoun, 'The Idea of Emergency: Humanitarian Action and Global (Dis)Order', in Fassin e Pandolfi (eds.), Contemporary States of Emergency, 30.

50 Didier Fassin, Humanitarian Reason: A Moral History of the Present, traduzido por Rachel Gomme (Berkeley, 2011), 145; Didier Fassin e Richard Rechtman, The Empire of Trauma: An Inquiry into the Condition of Victimhood, traduzido por Rachel Gomme (Princeton, 2009); Didier Fassin, 'From Rights to Favour: The Moral Economy of Asylum in Contemporary Society', palestra dada no Twenty-First Berlin Colloquium on Contemporary History, Einstein Forum, Potsdam, 3 de dezembro de 2015; Miriam Ticktin, Casualties of Care: Immigration and the Politics of Humanitarianism in France (Berkeley, 2011). Ver também Yves Dezalay e Bryant Garth, 'Droits de l'homme et philanthropie hégémonique', Actes de la recherche en sciences sociales, cxxi (1998); Gérard Noiriel, Réfugiés et sans-papiers: la République face au droit d'asile, XIX ${ }^{e}-X X^{e}$ siècle (Paris, 1998), edição revisada de La Tyrannie du national: le droit d'asile en Europe, 1793-1993 (Paris, 1991).

${ }^{51}$ Zain Lakhani, "Between Sex and Sovereignty: Refugee Women and the Politics of Border Control', Humanity (no prelo); Mary Nolan, 'Gender and Utopian Visions in a Post-Utopian Era: Americanism, Human Rights, Market Fundamentalism', Central European History, xliv (2011), 31.
} 
precisam reivindicar direitos a nações benevolentes tornando legíveis as suas experiências traumáticas, não como sujeitos políticos mas como corpos sofredores.

O novo humanitarianismo e os temas do idealismo dos direitos humanos fazem parte e são uma parcela do que Didier Fassin chama de "governo humanitário", a "política das vidas precárias". 52 Novamente, as consequências de tais ações morais e as desigualdades que delas surgem não são de modo nenhum novas; basta lembrar, por exemplo, as intervenções humanitárias do século XIX em nome do sofrimento dos cristãos otomanos. A novidade é a temporalidade de tais ações com base em um imaginário emergencial no aqui e agora, que suspende o tempo histórico (por isso a crítica da desistoricização feita por antropólogos contemporâneos) ${ }^{53}$ e dissolve as visões do anticolonialismo e do socialismo de um futuro em direção a uma modernização forçada. Nas palavras de Daniel Rodgers, "Pode-se alcançar nostalgicamente um fragmento do passado, mas o tempo que dominou o pensamento do final do século XX era o agora".54

\section{III}

Para concluir, devemos nos perguntar se a fratura do regime de tempo moderno também é uma dessas experiências de crise do final da Guerra Fria que levou à ascensão dos "direitos humanos" nos anos 1990. Seguindo Koselleck, o historiador francês François Hartog argumentou que a relação entre passado, presente e futuro é histórica por si mesma e que as experiências do tempo sofreram mudanças dramáticas no final do século XX. Até a Revolução Francesa,

Para críticas feministas legalistas, ver principalmente Alice M. Miller, 'Sexuality, Violence against Women, and Human Rights: Women Make Demands, and Ladies Get Protection', Health and Human Rights, vii (2004); Karen Engle, 'Feminism and its (Dis)Contents: Criminalizing Wartime Rape in Bosnia and Herzegovina', American Journal of International Law, xcix (2005); Janet Halley, 'Rape at Rome: Feminist Interventionism the Criminalization of Sex-Related Violence in Positive International Criminal Law', Michigan Journal of International Law, xxx (2008).

${ }^{52}$ Fassin, Humanitarian Reason, 4.

53 Ver a resenha de Nicolas Guilhot, 'The Anthropologist as Witness: Humanitarianism between Ethnography and Critique', Humanity, iii (2012).

${ }^{54}$ Daniel T. Rodgers, Age of Fracture (Cambridge, Mass., 2011), 255. 
era o cerne das ideologias revolucionárias. Por outro lado, depois de 1989, o presente avançou para o horizonte predominante de expectativas no mundo euro-atlântico. Sem futuro e sem passado, argumenta Hartog, o presente regenera o passado e o futuro apenas para valorizar o imediato. O futuro já não é mais visto como uma promessa, mas como uma ameaça, "não um horizonte radiante que guia o avanço de nossos passos, mas uma linha de sombra se aproximando, que nós mesmos colocamos em movimento". 55

O que parece fundamentalmente novo sobre o idealismo dos direitos humanos dos anos 1990 é precisamente o fato de que ele não é nem um pouco orientado ao futuro ou utópico. Não é um imaginário político ou social de uma sociedade diferente, mais perfeita. Pelo contrário, os direitos humanos individuais, em muitos sentidos, voltaram à ordem do dia primeiro como uma crítica das utopias revolucionárias, como apontado corretamente por Moyn. Após 1989, os direitos humanos tomaram o lugar desses futuros passados que perduraram até os anos 1970 e 1980, como a insistência pósimperial no direito de autodeterminação e em uma nova e mais justa ordem econômica internacional, ou na realização de direitos sociais e coletivos dentro do Estado-nação. Os direitos humanos desempenham esse papel em uma época marcada por uma crise das instituições de solidariedade e pelo advento de um novo tipo de capitalismo financeiro, que aumentou o abismo da desigualdade entre as nações: o que Pierre Rosanvallon chamou de "a grande inversão". 56 Ao final dos anos 1990, Michael Ignatieff via os direitos

\footnotetext{
55 François Hartog, Régimes d'historicité: présentisme et expériences du temps (Paris, 2003), traduzido por Saskia Brown como Regimes of Historicity: Presentism and Experiences of Time (New York, 2015), 113, 191. Ver também Andreas Huyssen, 'Present Pasts: Media, Politics, Amnesia', in Andreas Huyssen, Present Pasts: Urban Palimpsests and the Politics of Memory (Stanford, 2003); Chris Lorenz and Berber Bevernage (eds.), Breaking Up Time: Negotiating the Borders between Present, Past and Future (Göttingen, 2013).

56 Pierre Rosanvallon, La Société des égaux (Paris, 2011), traduzido por Arthur Goldhammer como The Society of Equals (Cambridge, Mass., 2013). Sobre a substituição "neoliberal" de direitos humanos
} 
humanos não mais como uma linguagem da justiça social global, mas como um "apenas um mínimo de humanidade”, “não muito além da intuição básica de que o que é dor e humilhação para você deve ser dor e humilhação mim".57 É para esse entendimento do final do século XX, de que os direitos humanos são vistos como empatia, para o qual Lynn Hunt fornece uma genealogia histórica.

Ao mesmo tempo, o passado também se transforma em uma história da violação das normas do presente (escravidão, genocídio) das quais, por sua vez, a legitimidade dessas normas é deduzida. Desde os anos 1990, o fracasso violento das visões do século $X X$ de futuros alternativos se tornou um termo de comparação para o nosso idealismo atual dos direitos humanos. Processar os crimes passados contra a humanidade opera cada vez mais em uma "atemporalidade legal", como observa Hartog. À medida que limitações temporais estatutárias para esses crimes caem, eles constituem um passado presente, um passado em julgamento, com historiadores transformados em testemunhas..$^{8} \mathrm{O}$ acirrado debate historiográfico da Historikerstreit alemã na metade dos anos 1980 girou em torno da questão se os crimes do nazismo e stalinismo poderiam ser colocados no mesmo quadro analítico e, de forma ainda mais provocadora, sequencial. Mais de duas décadas depois, Timothy Snyder fez precisamente isso em seu aclamado Terras de Sangue ao substituir as reflexões histórico-filosóficas de Ernst Nolte por descrições vívidas do sofrimento humano individual causado por ambos os regimes. 59 Os crimes de Hitler e Stalin, genocídio e limpeza étnica, se tornaram as "narrativas

e sociais, ver principalmente Susan Marks, Four Human Rights Myths, LSE Law, Society and Economy Working Papers, 10 (London, 2012); Mary Nolan, Human Rights and Market Fundamentalism, Max Weber Lecture Series, European University Institute, 2014/2 (Florence, 2014). Mais discreto é Samuel Moyn, 'A Powerless Companion: Human Rights in the Age of Neoliberalism', Law and Contemporary Problems, Ixxvii (2015). De forma mais geral, ver Nicolas Guilhot, The Democracy Makers: Human Rights and the Politics of Global Order (New York, 2005).

57 Ignatieff, Human Rights as Politics and Idolatry, 349. Para uma crítica da reinterpretação dos direitos humanos, ver Wendy Brown, "'The Most We Can Hope For...": Human Rights and the Politics of Fatalism', South Atlantic Quarterly, ciii (2004).

${ }^{58}$ Hartog, Regimes of Historicity, 200.

59 Timothy Snyder, Bloodlands: Europe between Hitler and Stalin (New York, 2010). 
Ao fim da Guerra Fria, Francis Fukuyama atraiu muita atenção, além de desprezo e escárnio, com sua tese sobre o fim da história. O seu artigo "O Fim da História?" foi publicado com aclamação mundial periódico neoconservador National Interest no verão de 1989, após o massacre da Praça da Paz Celestial, antes de se tornar um livro em 1992. ${ }^{62}$ Fukuyama, que na época trabalhava no Departamento de Estado, argumentou invocando Hegel e Kojève (além de Paul de Man, com quem havia estudado em Yale) que as revoltas em meados de 1989 significaram não só o fim da Guerra Fria e da ordem pós-guerra, mas o ponto final da evolução ideológica da humanidade e a universalização dos valores ocidentais como a forma final de governo humano em um mundo globalizado.

O advento da posthistoire tem sido parte crucial do pensamento político tanto da esquerda quanto da direita desde os anos 1940.63 Assim, mesmo que a tese de Fukuyama não fosse nova, ele articulou a mudança na experiência do tempo que Hartog havia estabelecido para os anos em torno de 1989. De forma mais precisa, o idealismo dos direitos humanos das elites euro-atlânticas dos anos 1990 serviu como esparadrapo, cobrindo o fato de que nesse novo mundo - mesmo após o fim da história, ou seja, o fim de futuros alternativos - guerras civis, genocídio e fundamentalismos religiosos e ideológicos de todo tipo ainda não haviam ficado completamente no passado. A moralidade dos

\footnotetext{
60 Charles S. Maier, 'Consigning the Twentieth Century to History: Alternative Narratives for the Modern Era', American Historical Review, cv (2000).

${ }^{61}$ Linda K. Kerber, 'From the President: We Are All Historians of Human Rights', Perspectives on History: The Newsmagazine of the American Historical Association (Oct. 2006).

62 Francis Fukuyama, 'The End of History?', National Interest, 16 (1989); Francis Fukuyama, The End of History and the Last Man (New York, 1992).

63 Lutz Niethammer em colaboração com Dirk van Laak, Posthistoire: ist die Geschichte zu Ende? (Reinbek bei Hamburg, 1989), traduzido por Patrick Camiller como Posthistoire: Has History Come to an End? (London, 1994).
} 
direitos humanos se tornou, como observou Hans Magnus Enzensberger em 1993, "o último refúgio do eurocentrismo". 64

Isso significa, então, que os direitos humanos não possuem história, pelo menos não uma história que comece no nosso próprio presente? Pois essa seria a consequência da historiografia revisionista dos direitos humanos que eu fiz avançar até os anos 1990. Mas isso não tornaria a nova historiografia dos direitos humanos mais uma iteração da síndrome do presentismo, "o sentido de que somente o presente existe, um presente caracterizado, ao mesmo tempo, pela tirania do instante e pela esteira de um agora sem fim"? ${ }^{65}$ A fim de evitar a armadilha historiográfica contrária de fazer história ao revés projetando o nosso entendimento atual de direitos humanos individuais para o passado, é necessário integrar a história de reinvindicações políticas ou sociais alternativas, como o futuro passado ou a modernidade pós-colonial, na história dos direitos humanos.

Histórias mais recentes dos direitos humanos podem ter-se interessado quase que exclusivamente na versão dos direitos humanos focada nos indivíduos sofredores. Citando o exemplo do anticolonialismo, Moyn, por exemplo, contesta explicitamente se as noções anteriores de direitos humanos, que abarcavam também direitos coletivos, pertencem mesmo à história dos direitos humanos. ${ }^{66}$ E na história de Hunt do surgimento da empatia imaginada como fonte das reinvindicações dos direitos humanos durante a Revolução Francesa, os direitos sociais ("a transformação dos Direitos do Homem nos direitos dos SansCulottes", na formulação desdenhosa de Arendt), 67 tais como o direito ao trabalho, não são sequer mencionadas, apesar de constituírem a parte central da Declaração jacobina dos Direitos do Homem e do Cidadão do de 1793 (e estão, é

\footnotetext{
${ }^{64}$ Hans Magnus Enzensberger, Aussichten auf den Bürgerkrieg (Frankfurt, 1993), 77.

${ }^{65}$ Hartog, Regimes of Historicity, p. xv. Ver também a crítica de Philip Alston, 'Does the Past Matter? On the Origins of Human Rights. An Analysis of Competing Histories of the Origins of International Human Rights Law', Harvard Law Review, cxxvi (2013); e uma perspectiva diferente, por Robin Blackburn, 'Reclaiming Human Rights', New Left Review, Ixix (2011); Robin Blackburn, The American Crucible: Slavery, Emancipation and Human Rights (London, 2011), ch. 14.

${ }^{66}$ Moyn, Last Utopia, 86; Samuel Moyn, 'Imperialism, Self-Determination, and the Rise of Human Rights', in Iriye, Goedde and Hitchcock (eds.), Human Rights Revolution. Similarmente, Jan Eckel, 'Human Rights and Decolonization: New Perspectives and Open Questions', Humanity, i (2010).

67 Hannah Arendt, 'The Social Question', in Hannah Arendt, On Revolution (London, 1994), 61.
} 
claro, incluídas na Declaração Universal dos Direitos Humanos de 1948). O direito dos povos à autodeterminação, ${ }^{68}$ mas também a história dos direitos sociais e econômicos da Revolução Francesa até os anos 1960 e 1970, quando foram principalmente os Estados pós-coloniais que pressionaram por uma maior igualdade global - todos esses são, de uma perspectiva do direito internacional, parte dos direitos humanos internacionais reconhecidos pelas Nações Unidas. Entretanto, eles não aparecem em Moyn, Hunt ou boa parte da historiografia recente, precisamente porque eles foram definidos a partir da versão hegemônica dos direitos humanos ao longo das últimas duas décadas. ${ }^{69} \mathrm{~A}$ reintrodução de direitos sociais e econômicos na história dos direitos humanos permite uma avaliação melhor qualificada da ascensão dos direitos humanos individuais no final dos anos 1970 e seu "avanço" após o final da Guerra Fria.

Se o argumento aqui desenvolvido é correto - que a ênfase recente dos direitos humanos como individuais, pré-Estado e preocupados primeiramente com o sofrimento distante que ressurgiu como resultado de uma virada ética dos "anos 1990 globais", e que substituiu ou ultrapassou noções anteriores dos direitos humanos como o internacionalismo, que se centravam nos direitos de grupos, soberania e justiça social - então os direitos humanos possuem, sim, uma história alternativa, uma história que narra reinvindicações e contrarreivindicações concorrentes de direitos, todas baseadas em nossa "humanidade" em comum.70 Se as concepções contemporâneas de direitos humanos têm mais semelhanças com o mundo dos séculos XVIII e XIX do que

\footnotetext{
${ }^{68}$ Ver principalmente Jörg Fisch, Das Selbstbestimmungsrecht der Völker: die Domestizierung einer Illusion (Munich, 2010), traduzido por Anita Mage como The Right of Self-Determination of Peoples: The Domestication of an Illusion (Cambridge, 2015); Brad Simpson, 'The United States and the Curious History of Self-Determination', Diplomatic History, xxxvi (2012).

${ }^{69}$ Entretanto, ver as constribuições para Humanity, iii, 3, Dossier on Social Rights and Human Rights in the Twentieth Century, ed. Malgorzata Mazurek e Paul Betts (2012), especialmente Frederick Cooper, 'Afterword: Social Rights and Human Rights in the Time of Decolonization'; Humanity, vi, 1, special issue, Toward a History of the New International Economic Order, ed. Nils Gilman (2015). De forma mais geral, Alain Supiot, L'Esprit de Philadelphie: la justice sociale face au marché total (Paris, 2010), traduzido por Saskia Brown como The Spirit of Philadelphia: Social Justice vs. the Total Market (London, 2012); Gregory Claeys, 'Socialism and the Language of Rights: The Origins and Implications of Economic Rights', in Pamela Slotte e Miia Halme-Tuomisaari (eds.), Revisiting the Origins of Human Rights (Cambridge, 2015); Mira L. Siegelberg, 'Neither Right nor Left: Interwar Internationalism between Justice and Order', Humanity, vi (2015).

${ }^{70}$ Hoffmann, 'Genealogies of Human Rights', 4.
} 
com o internacionalismo da era da Guerra Fria, por exemplo, então a história dos direitos humanos deveria ser expandida para incluir uma história moral do século após o lluminismo, um século que Moyn e Hunt, de certo modo, preteriram. Conquanto o conceito de direitos humanos não tenha sido central para as campanhas morais vitorianas do século XIX, o foco dos movimentos reformistas nos detalhes, a narrativa e a empatia com um sofrimento corporal distante, por exemplo, lembram, de vários modos, o novo humanitarianismo despolitizado dos direitos humanos que surgiu no final dos anos 1960 e começo dos 1970 em Biafra e Bangladesh e se tornou hegemônico nos anos 1990. ${ }^{71}$

Alguns dos paradoxos discutidos por acadêmicas feministas atualmente, à luz da ênfase recente no sofrimento corporal e violência sexual para avançar reivindicações de direitos humanos em nome das mulheres, são bastante familiares para os historiadores do movimento de reforma moral feminina do século XIX ou da luta pelos direitos cidadãos das mulheres. É claro, é importante e fácil o suficiente apontar o abismo que separa, por exemplo, as sufragistas de antes de 1914 do movimento feminista do final do século $X X$, ou a preocupação vitoriana com a prostituição feminina das campanhas atuais contra o tráfico sexual internacional. Entretanto, se excluirmos a história dos direitos da mulher desde a Revolução Francesa da história dos direitos humanos, não seremos capazes de entender a latência

\footnotetext{
${ }^{71}$ Thomas W. Laqueur, 'Bodies, Details, and the Humanitarian Narrative', in Lynn Hunt (ed.), The New Cultural History (Berkeley, 1989); Thomas W. Laqueur, 'Mourning, Pity, and the Work of Narrative in the Making of "Humanity", in Richard Ashby Wilson and Richard D. Brown (eds.), Humanitarianism and Suffering: The Mobilization of Empathy (Cambridge, 2009); Thomas L. Haskell, 'Capitalism and the Origins of the Humanitarian Sensibility', American Historical Review, xc, 2-3 (pts 1 and 2) (1985); Kevin Grant, A Civilised Savagery: Britain and the New Slaveries in Africa, 1884-1926 (New York, 2005); Davide Rodogno, Against Massacre: Humanitarian Interventions in the Ottoman Empire, 1815-1914. The Emergence of a European Concept and International Practice (Princeton, 2012); Kevin Grant, 'The Limits of Exposure: Atrocity Photographs in the Congo Reform Campaign', in Fehrenbach e Rodogno (eds.), Humanitarian Photography; Abigail Green, 'Humanitarianism in Nineteenth-Century Context: Religious, Gendered, National', Historical Journal, Ivii (2014); Bronwen Everill and Josiah Kaplan (eds.), The History and Practice of Humanitarian Intervention and Aid in Africa (Basingstoke, 2013); Fabian Klose (ed.), The Emergence of Humanitarian Intervention: Ideas and Practice from the Nineteenth Century to the Present (Cambridge, 2016).
} 
de direito internacional e política internacional de séculos anteriores desempenharam uma função semelhante à dos direitos humanos individuais e préEstado hoje. Mark Mazower apontou que, na disjuntura da metade do século XX dos anos 40, "os direitos humanos" tomaram o lugar do conceito de "civilização", que havia estruturado o direito internacional durante o século XIX.73 A erosão da soberania do Estado desde os anos 1990 foi acompanhada por um retorno dessa retórica mais antiga da ética universal que era ligada ao conceito de civilização ou civilidade. Enquanto que a ordem política internacional posterior à Segunda Guerra Mundial e ao fim dos impérios era baseada na igualdade formal dos Estados, a invocação de direitos humanos individuais pré-Estado (particularmente a doutrina da "responsabilidade de proteger") reintroduziu na política e no direito internacionais a hierarquia dos Estados civilizados e não-civilizados que, no século XIX, levaram à justificativa de intervenções humanitárias, por exemplo, no Império Otomano.74 Assim, os historiadores contemporâneos dos direitos humanos têm mais a aprender com a história do longo século XIX do que eles imaginam. Pois, se continuarmos a contar essa história de forma míope como o avanço das nossas noções de direitos humanos individuais, nós "perpetuaremos precisamente os tipos de hierarquia que a linguagem dos direitos, em seus melhores dias, tentou desmantelar". 75

\footnotetext{
72 Joan Wallach Scott, Only Paradoxes to Offer: French Feminists and the Rights of Man (Cambridge, 1996). Ver também, por exemplo, Gretchen Soderlund, 'Running from the Rescuers: New US Crusades against Sex Trafficking and the Rhetoric of Abolition', NWSA Journal, xvii (2005); Gretchen Soderlund, Sex Trafficking, Scandal, and the Transformation of Journalism, 1885-1917 (Chicago, 2013).

73 Mark Mazower, 'The End of Civilization and the Rise of Human Rights: The Mid-Twentieth Century Disjuncture', in Hoffmann (ed.), Human Rights in the Twentieth Century; Mark Mazower, No Enchanted Palace: The End of Empire and the Ideological Origins of the United Nations (Princeton, 2009); Mazower, Governing the World. Ver também Martti Koskenniemi, The Gentle Civilizer of Nations: The Rise and Fall of International Law, 1870-1960 (Cambridge, 2001); Glenda Sluga, Internationalism in the Age of Nationalism (Philadelphia, 2013).

74 Comparar, por exemplo, com Rodogno, Against Massacre, com Anne Orford, International Authority and the Responsibility to Protect (Cambridge, 2011).

75 Martti Koskenniemi, 'Foreword: History of Human Rights as Political Intervention in the Present', in Slotte e Halme-Tuomisaari (eds.), Revisiting the Origins of Human Rights, p. xviii.
} 
